\title{
Acid Aging of CFRP Composite Materials for Solar UAV Structure
}

\author{
Bing Shen $\mathbb{D}^{1},{ }^{1}$ HongJun Liu $\mathbb{D}{ }^{2}$, Shengli Lv $\mathbb{D},{ }^{2}$ Zheng Li $\mathbb{D}^{2},{ }^{2}$ and Wen Cheng $\mathbb{D}^{3}$ \\ ${ }^{1}$ School of Aeronautics, Northwestern Polytechnical University, Xi'an 710072, China \\ ${ }^{2}$ Science and Technology on UAV Laboratory, Northwestern Polytechnical University, Xi'an 710065, China \\ ${ }^{3}$ School of Mechatronic Engineering Xi'an Technological University, Xi'an 710021, China \\ Correspondence should be addressed to Bing Shen; shenbing198881@mail.nwpu.edu.cn
}

Received 24 August 2021; Revised 8 September 2021; Accepted 15 September 2021; Published 15 October 2021

Academic Editor: Nicolas Avdelidis

Copyright (C) 2021 Bing Shen et al. This is an open access article distributed under the Creative Commons Attribution License, which permits unrestricted use, distribution, and reproduction in any medium, provided the original work is properly cited.

\begin{abstract}
The purpose of this investigation is to study the performance degradation mechanism of CRRP composite materials used in the structure of a solar UAV under acid rain environment and to provide references for the structural design of the solar UAV. An aging test was designed according to the actual working conditions of the solar unmanned aerial vehicle and was carried out by continuously immersing the composite material in both deionized water and an acidic solution with a $\mathrm{pH}$ of 2.0 at $60^{\circ} \mathrm{C}$. The mechanical behavior of the composites was studied through a three-point bending test. The results showed that after 120 days of aging test, the composite material exhibits different characteristics in the two conditions. The composite material under the hygrothermal conditions finally reached the equilibrium moisture absorption content of $1.07 \%$, and the flexural strength decreased by $8.77 \%$. The composite material under acidic conditions deviated from the Fick behavior in the final stage of the test, and the final moisture content was $2.88 \%$, and the bending strength decreased by $26.43 \%$. Several typical empirical models were analyzed, and a hyperbolic tangent function empirical model with moisture content as the main variable was used to predict the CFRP flexural strength degradation process, and good results were obtained. The effect of aging conditions on the microstructure of composite materials was observed by SEM, and the aging mechanism of composite materials was analyzed. The corrosion of the polymer matrix and the debonding of the fiber/matrix interface are the root causes of the performance degradation of composite materials.
\end{abstract}

\section{Introduction}

Fiber-reinforced polymer (FRP) composites have become the most promising structural materials of present century. Their high specific strength and high specific stiffness have made them find applications in variable engineering fields, including aerospace, transportation, civil facilities, and maritime facilities [1-5]. Especially in the field of UAVs, the excellent mechanical properties have great significance to the lightweight structure design [6-8]. The high strength and toughness of fiber-reinforced composite materials are achieved by introducing high-strength fibers into the matrix material to form an interface between the fibers and the matrix. The appearance of the interface makes the composite material dissipate more energy in the process of deformation, damage, and destruction.

However, the microstructure characteristics of fiberreinforced composites make them very sensitive to hydro- thermal environments. Thermoset resin presented in composite materials, such as epoxy resins, absorbs the moisture in during operations in hydrothermal environments. The water molecules that entered the composite material during the moisture absorption are usually divided into unbound molecules and bound molecules. Unbound molecules diffuse into the internal pores and cracks of the composite materials, without reacting with the resin matrix; therefore, the polymer does not swell and plasticize. The bound molecules combined with the epoxy hydrophilic group destroy the polymer chain and lead to the expansion and plasticization of the epoxy resin $[9,10]$.

The effects of temperature and moisture on the CFRP can be summarized as follows [11]:

(1) The glass transition temperature $T_{g}$ of the polymer changes under the influence of temperature and moisture, resulting in a decrease in the mechanical 
properties of the matrix, thereby affecting the stiffness and strength of the composite material

(2) The matrix and fibers expand or contract due to temperature and moisture changes, and the inconsistent expansion/contraction behaviour results in residual stress

(3) The intrusion of moisture weakens the bonding strength between the fiber/matrix

Under some special conditions, a hydrothermal environment is often accompanied by the influence of chemical media, such as acid rain condition. In the research, it is necessary to pay attention to the effect of acidic substances during the aging of composite materials. Firstly, acid corrosion causes the pores and cracks inside the composite material to expand, which intensifies the hygroscopic behaviour, which is the key factor that causes the strength degradation. Secondly, immersion in an acid solution will also cause the glass transition temperature of the resin to change, which leads to a significant decrease of mechanical properties.

Feng et al. [12] exposed pultruded GFRP composite material to acidic, alkaline, and seawater environments and studied the effect of corrosive environments on material properties. The study found that the flexural strength decreased with the increase of exposure time in acidic and alkaline solutions, while saturated $\mathrm{NaCl}$ solution had little effect on GFRP. Banna et al. [13] exposed the polyester and bisphenol A epoxy vinyl ester resin to two different acidic solutions at two different temperatures $\left(25^{\circ} \mathrm{C}\right.$ and $75^{\circ} \mathrm{C}$ ). The results showed that the flexural performance and hardness of the resin under acidic conditions have significantly decreased. The microstructure of polyester degraded further under high temperature acidic environment, and the surface roughness increased. Mortas et al. [14] studied the low-speed impact response of Kevlar/epoxy laminates and carbon/epoxy laminates immersed in hydrochloric acid $(\mathrm{HCl})$ and sodium hydroxide $(\mathrm{NaOH})$. The results showed that aggressive solutions significantly affected the impact strength, but its effect depended largely on the concentration of the solution. In addition, temperature also had a significant effect on impact performance and residual flexural strength. Amaro et al. [15] analyzed the flexural properties and impact strength of glass fiber/epoxy resin composites immersed in hydrochloric acid and sodium hydroxide solutions. In both solutions, the flexural strength and flexural modulus decreased with exposure time. Compared with acidic solutions, alkaline solutions had a greater impact on bending performance and impact strength. Kanerva et al. [16] revealed the role of fiber-to-matrix interfacial aging on elastic constants due to a long-term sulfuric acid immersion at a high temperature. The experimental results showed that the aging significantly affects tensile and flexural behaviour of glass fiber vinylester epoxy composites: tensile and flexural stiffness decreased about 6-49\%, and ultimate strength values decreased about $13-34 \%$. The simulations presented that the degradation of fiber matrix interfaces might be a key factor of the degradation of GFRP modulus. Kattaguri et al. [17] studied the effect of seawater
$(\mathrm{pH}=8.2)$, alkaline $(\mathrm{pH}=13)$, and acidic $(\mathrm{pH}=1)$ solution aging on the GE composites with and without CNF reinforcement by an aging test which has been carried out for 150 days. It was revealed that as the immersion time increases, there was a continuous decrement in flexural strength and modulus, and glass-transition temperature $\left(T_{g}\right)$ of all the materials in all these solutions.

Many literatures have proposed quantitative methods for the degradation of mechanical properties of composite materials caused by environmental aging, and it is generally believed that this degradation is related to aging time or moisture content. However, even if the immersion time is the same, considering the difference in the porosity and interface strength, the moisture content of the specimens may vary. Therefore, it is more convincing to describe the performance degradation of composite materials in terms of changes in moisture content and glass transition temperature. The existing empirical models describing degradation mainly take immersion time [18-23], moisture content [24, 25], and glass transition temperature $[26,27]$ as key variables.

In this paper, an acid aging test was designed to simulate the acid rain condition of solar-powered UAV in service, and a three-point bending test was used to study the strength degradation of carbon fiber-reinforced composite material. A hyperbolic function empirical model was used to predict the relationship between flexural strength degradation and moisture content. The fitness of the model with experimental data was also compared with the fitness of other models from the literature. The change of the microstructure in the damaged area before and after aging reflected the mechanism of aging on the strength degradation.

\section{Materials}

Composite panels for proceeding specimens were manufactured using unidirectional T300 carbon fiber-reinforced epoxy prepregs (nominal ply thickness is $0.185 \mathrm{~mm}$ ) with symmetric lay-up $[0 / 90]_{4 s}$. A vacuum bag manufacturing route was employed in order to consolidate the prepregs. The prepregs were stacked on the aluminum alloy mold and placed into an oven. The consolidation temperature should use a heat-up rate at $3^{\circ} \mathrm{C} / \mathrm{min}$ and hold at $150^{\circ} \mathrm{C}$ for 30 minutes, then demold at below $80^{\circ} \mathrm{C}$.

\section{Methodology}

3.1. Aging Tests. In aging tests, the diffusion of moisture is usually carried out in a humid or natural aging condition by immersing the composite material specimens in distilled water or artificial seawater at room temperature. Hydrothermal aging is a kind of accelerated aging, which has increased the temperature of the testing condition to aggravate the diffusion behaviour without affecting the testing mechanism. With this method, the efficiency of the aging test is improved and the test period is significantly shortened [28, 29].

According to the data collected during the flight of the solar-powered UAV, due to solar radiation and electronic equipment heat dissipation, the surface temperature of the aircraft could reach $85^{\circ} \mathrm{C}$ during the day, and the internal 
temperature of the aircraft structure could be above $55^{\circ} \mathrm{C}$. The aging test was carried out by immersing the composite material specimens into deionized water and acidic solution with a $\mathrm{pH}$ of 2.0 at $60^{\circ} \mathrm{C}$ for 120 days. The aged specimens were immediately weighed after being taken out from the aging conditions, and the moisture content of the composite material was calculated to determine the absorption characteristics.

3.2. Three-Point Bending Tests. The bending test was carried out according to the three-point bending method in the test standard ASTM D7264 [30]. The schematic diagram of the specimen and test is shown in Figure 1. The relevant parameters of the three-point bending test are shown in Table 1. The three-point bending test was conducted on the Instron5848 Micro Tester with a loading displacement rate of $1 \mathrm{~mm} / \mathrm{min}$.

\section{Results and Discussion}

4.1. Moisture Diffusion. The moisture absorption characteristics of the composite material were tested and calculated according to test standard ASTM D5229 [31], and the weight measurement accuracy was $0.1 \mathrm{mg}$. The moisture content of the specimen was calculated by

$$
M=\left|\frac{W_{i}-W_{d}}{W_{d}}\right| \times 100 \%
$$

where $W_{d}$ is the dry specimen mass measured before immersion and $W_{i}$ is the aged specimen mass measured during the aging test.

The Fick law applied to single free phase diffusion is the most common approach to model moisture absorption. It predicts that the moisture content linearly increases with the square root of time and gradually slows until a saturation is achieved [32]. In this method, the mass diffusion coefficient $D_{z}$ is calculated by Equation (2) as follows:

$$
D_{z}=\pi\left(\frac{h}{4 M_{m}}\right)^{2}\left(\frac{M_{2}-M_{1}}{\sqrt{t_{2}}-\sqrt{t_{1}}}\right)^{2},
$$

where $h$ is the thickness of the specimen, $M_{2}-M_{1}$ is the slope of moisture absorption plot in the initial, and $\sqrt{t_{2}}-\sqrt{t_{1}}$ is the linear portion of the curve.

The typical Fick diffusion process can be described by

$$
G=\frac{M-M_{i}}{M_{m}-M_{i}}=1-\frac{8}{\pi^{2}} \sum_{j-0}^{\infty} \frac{1}{(2 j+1)^{2}} \exp \left[\frac{-(2 j+1)^{2} \pi^{2} D_{z} t}{h^{2}}\right],
$$

where $M$ is the moisture content, $M_{i}$ is the original moisture content, and $M_{m}$ is the moisture content at equilibrium.
In most cases, Equation (3) can be approximately transformed into

$$
G=1-\exp \left[-7.3\left(\frac{D_{z} t}{h^{2}}\right)^{0.75}\right] .
$$

The distribution of the moisture absorption of the aged specimens with time is shown in Figure 2. During the initial period of the aging test, the average moisture content of the specimens in both aging conditions were close, reaching $0.51 \%$ and $0.65 \%$, respectively. Subsequently, the moisture absorption rate of the hydrothermal specimens slowed down significantly and basically reached an equilibrium status in about 40 days. The saturated moisture content of hydrothermal specimens was about $1.07 \%$.

At the same time, despite the slight slowdown in the rate of moisture absorption, the acid-aged specimens always showed obvious moisture absorption behaviour. Until the end of the aging test, the moisture content reached $2.88 \%$, but still did not reach a fully saturated status. Moreover, the moisture process in the acid aging test deviated from Fick's law in the final period of the test. The reason for this phenomenon was probably due to the corrosive effect of the acidic substance, which caused the expansion of the pores and microcracks inside the specimens. The generation of new cracks makes the free volume inside the composite material larger and aggravates the diffusion behaviour of the solution into the composite material. This possibility was confirmed in subsequent SEM observation.

4.2. Flexural Properties. The load-displacement data obtained was processed according to ASTM D7264 to calculate the bending properties of the specimens. The flexural strength and flexural modulus were calculated according to

$$
\begin{aligned}
& \sigma=\frac{3 P D}{2 b h^{2}}, \\
& E=\frac{\Delta \sigma}{\Delta \varepsilon},
\end{aligned}
$$

where $\sigma$ is the stress at the outer surface at mid-span, $P$ is the applied force, $L$ is the support span, $b$ is the width of specimen, $h$ is the thickness of specimen, $E$ is the flexural chord modulus of elasticity, $\Delta \sigma$ is the difference in flexural stress between the two selected strain points, and $\Delta \varepsilon$ is the difference between the two selected strain points (nominally 0.002).

The distribution of flexural properties with aging time and moisture content is shown in Figures 3-5. As shown in Figure 4, the change in flexural modulus of the specimens with time under the two aging environments is negligible. Figures 4 and 5 show the flexural strength as a function of aging time and moisture content. Obviously, the aging effect of the acidic environment on the carbon-fiber-reinforced epoxy resin-based composite material is significantly stronger than that of the hydrothermal environment.

The acid aging test can be roughly divided into three stages. In stage one, the moisture absorption rate increased rapidly, but the attenuation of flexural strength is slight, 

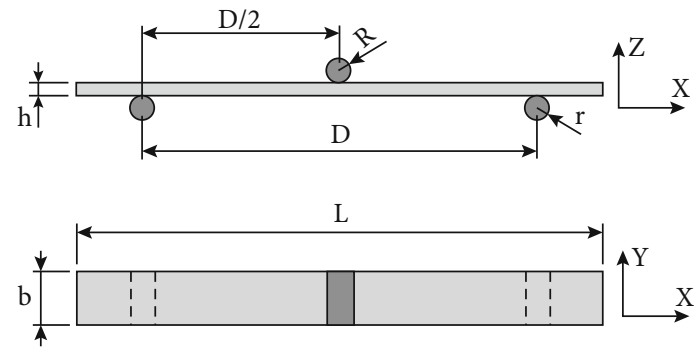

(a)

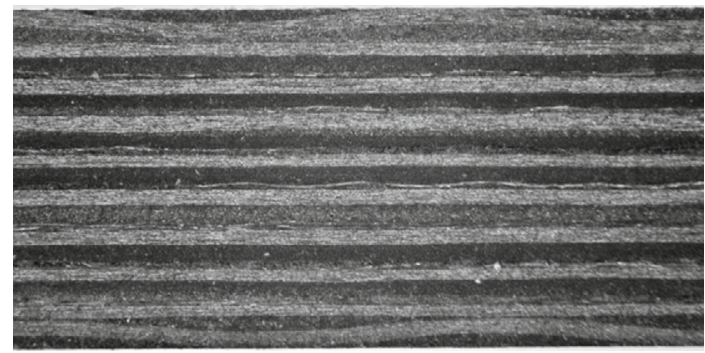

(b)

Figure 1: The load configuration of three-point bending experiment: (a) schematic of the flexural test specimens and (b) flexural test specimen layup.

TABLE 1: The parameters of three-point bending experiments.

\begin{tabular}{lcc}
\hline Parameter & Symbol & Value $(\mathrm{mm})$ \\
\hline Length & $\mathrm{L}$ & 120 \\
Width & $\mathrm{B}$ & 13 \\
Thickness & $\mathrm{h}$ & 3 \\
Support span & $\mathrm{D}$ & 96 \\
Loading nose radius & $\mathrm{R}$ & 5 \\
Support radius & $\mathrm{r}$ & 5 \\
\hline
\end{tabular}

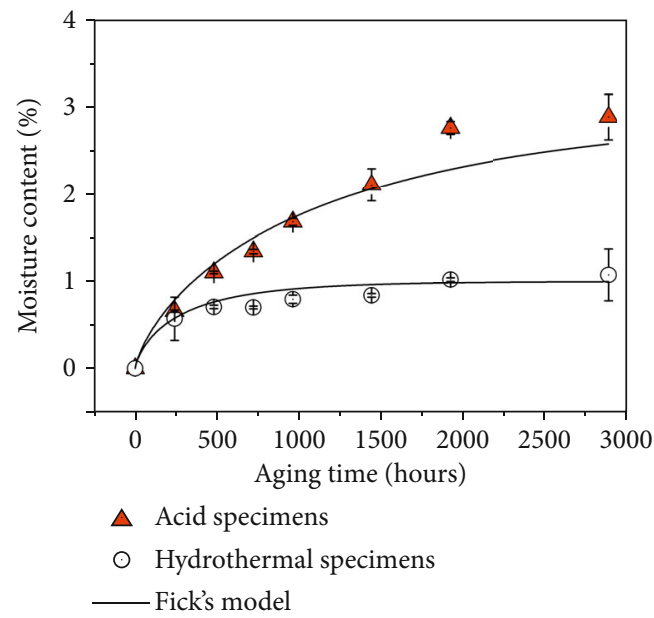

Figure 2: Moisture absorption content distribution over time.

which meant that the acidic solution entered the microcracks and pores inside the specimens without having a major impact on the resin matrix. In stage two, the corrosive effect of the acidic solution on the resin matrix aggravated the moisture absorption behaviour; meanwhile, the rapid diffusion of the acid solution severely damaged the microstructure of the composite material and affected the strength of the material. In the third stage, although the moisture absorption rate was still increasing, the damage effect of the acid solution on the microstructure of the composite material was close to the saturated state, and the strength degradation phenomenon gradually slowed down.

4.3. Empirical Models. When predicting the long-term mechanical properties of fiber-reinforced polymer matrix composites in the environment, common empirical models mainly use aging time as the main parameter, and the most typical one is the Phani model. Phani and Bose [18] developed an exponential decay model as shown in Equation (6) to predict the flexural strength degradation of glass fiberreinforced polyester composites immersed in distilled water at $60^{\circ} \mathrm{C}$ and $80^{\circ} \mathrm{C}$. Gautier et al. [19] and Sun et al. [20] used this model to study the degradation of interlaminar strength of different composites and achieved good results. Guo et al. [21] combined the Phani model and the multiscale finite element method (FEM) to study the damp and heat aging behaviour of carbon fiber-reinforced epoxy resin composites, revealing the relationship between microstructure evolution and macroperformance degradation. Tanks et al. [22] modified the original Phani model in order to distinguish the difference between the aging mechanisms of carbon/epoxy and E glass/polyester composites.

$$
\sigma_{t}=\left(\sigma_{0}-\sigma_{\infty}\right) \exp \left(\frac{-t}{\tau}\right)+\sigma_{\infty}
$$

where $\sigma_{t}$ is the aged strength property at the immersion time $t, \sigma_{0}$ is the dry material strength, $\sigma_{r}$ is the aged strength at the equilibrium moisture absorption rate, and $\tau$ is characteristic time dependent on temperature.

Phillips [23] established an exponential model to predict the fracture life of glass fiber-reinforced polyester composites under long-term stress conditions in a hydrothermal environment, as shown in

$$
\sigma_{t}=(a-\operatorname{blog} t) \sigma_{0}
$$

where $a$ and $b$ are the empirical constants and $t$ is immersion time.

Models of Phani and Philips were used to fit the experimental data under hydrothermal aging and acid aging conditions, respectively, and the process of flexural strength degradation over time was described, as shown in Figures 6(a) and 6(b). The fitting results of the two models and experimental data showed a good correlation, but the different stages of strength degradation process in acidic condition were not reflected clearly.

The difference in the degree of matrix curing and porosity results in composite materials under the same aging time 


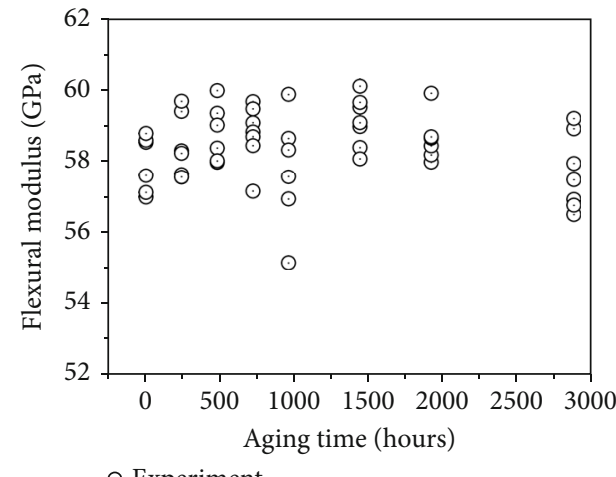

$\odot$ Experiment

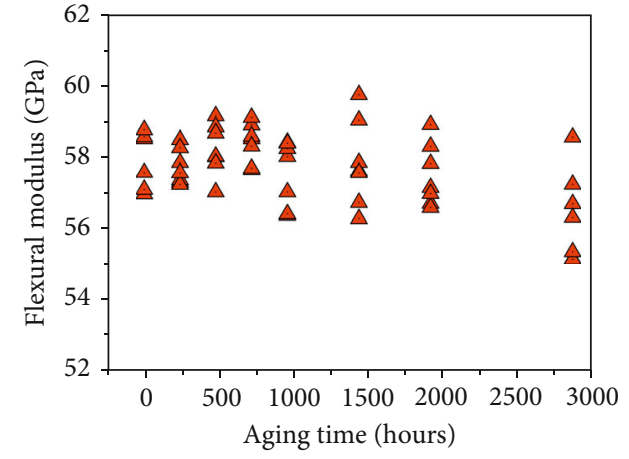

$\Delta$ Experiment

(a)

(b)

Figure 3: Flexural modulus as a function of aging time: (a) hydrothermal aging and (b) acid aging.

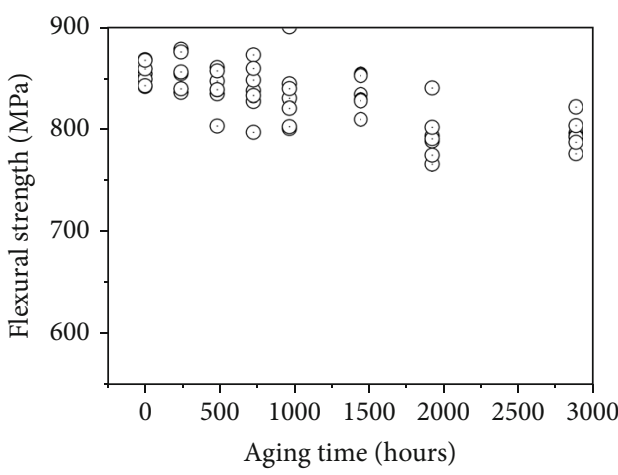

○ Experiment

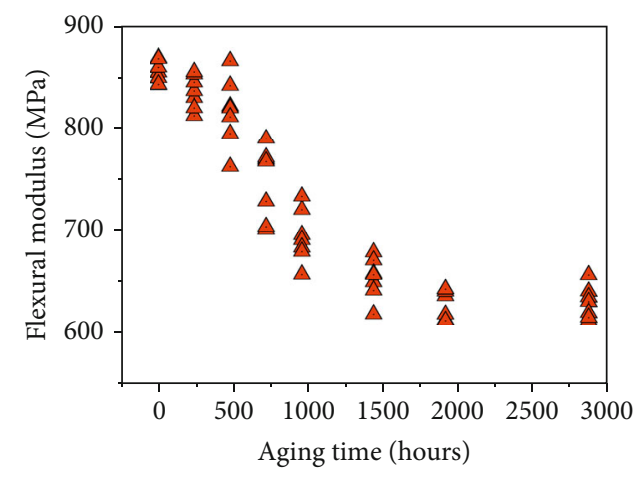

$\Delta$ Experiment

(a)

(b)

Figure 4: Flexural strength as a function of aging time: (a) hydrothermal aging and (b) acid aging.

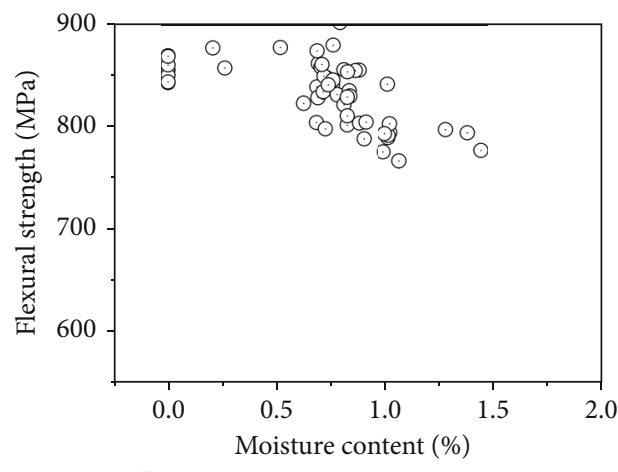

○ Experiment

(a)

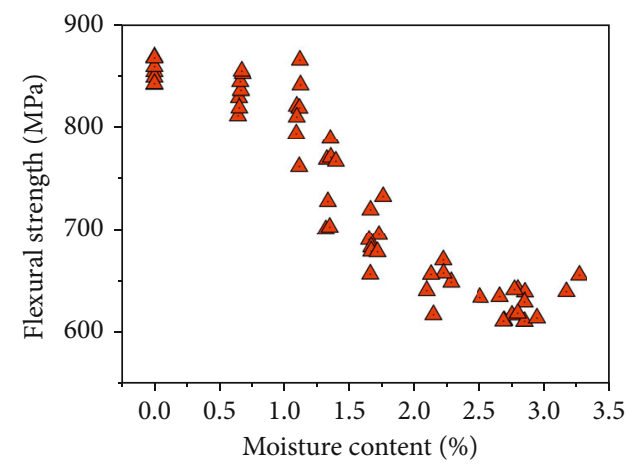

(b)

FIGURE 5: Flexural strength as a function of moisture content: (a) hydrothermal aging and (b) acid aging.

that may have different moisture absorption contents and changes in mechanical properties. Therefore, researchers have proposed empirical models related to moisture absorption content. Pritchard and Speake [24] studied the mechanical properties of glass fiber polyester resin composite laminates after long-term immersion in water and found that these changes are a function of moisture absorption.
They established an exponential model with moisture absorption as a parameter variable to predict the change in tensile properties of glass fiber-reinforced polyester composites in a hydrothermal environment and obtained good experimental verification results. Papanicolaou et al. [25] established an exponential model to predict the tensile strength and modulus changes of Epikote 828 epoxy resin 


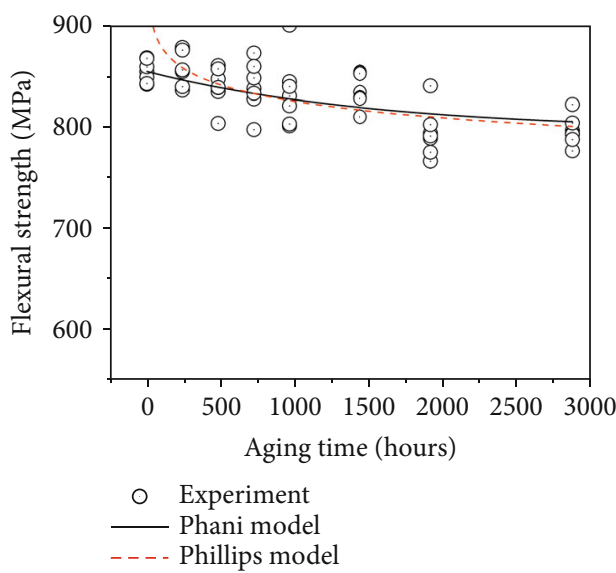

(a)

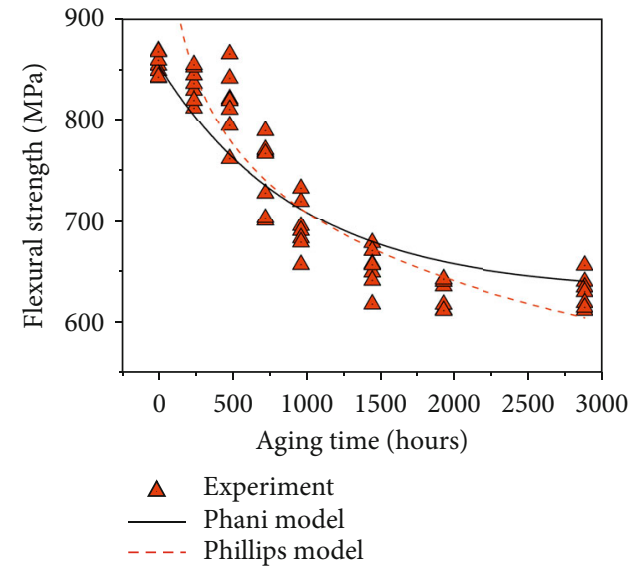

(b)

FIgURE 6: Experimental data fitted to aging time: (a) hydrothermal aging and (b) acid aging.

in hydrothermal environment, as shown in Equation (7). Using these two empirical models for data fitting, the results are shown in Figure 7.

$$
\sigma_{m}=a\left(1-e^{-b e^{-c M}}\right)+d
$$

where $\sigma_{m}$ is the residual property at moisture content and $M, a, b, c$, and $d$ are empirical constants.

$$
\sigma_{m}=\left[s+(1-s) \mathrm{e}^{-s M}\right] \sigma_{0}
$$

where $\sigma_{0}$ is the property for the dry specimen and $s$ is the ratio of the residual property value at the saturation level to the value of the same property for the dry material.

Through a large amount of experimental data analysis, Gibson et al. [26] proposed a model for predicting the degradation of mechanical properties of composite materials during high-temperature ablation, shown as Equation (10). In this model, the environmental temperature and glass transition temperature were the main function variables, and the parameter $R^{n}$ was introduced to describe the strength degradation caused by the combustion and decomposition of the resin matrix.

$$
P(T)=\left\{\frac{P_{U}+P_{R}}{2}-\frac{P_{U}-P_{R}}{2} \tan h\left[k\left(T-T^{\prime}\right)\right]\right\} R^{n},
$$

where $P(T)$ is a particular property, $P_{U}$ and $P_{R}$ are the unrelaxed (low temperature) and relaxed (high temperature) values of that property, $k$ is a constant describing the breadth of the distribution, $T$ is the temperature variable, and $\mathrm{T}^{\prime}$ is the mechanically determined glass transition temperature.

Cao et al. [27] modified Equation (10) and proposed a semiempirical model related to the glass transition temperature to describe the degradation of CFRP tensile strength caused by high temperature, shown as

$$
\sigma=\frac{\sigma_{0}+\sigma_{r}}{2}+\frac{\sigma_{0}-\sigma_{r}}{2} \tan h\left\{\frac{-1}{\Delta T / 2}\left[T-\left(T_{g}+\frac{\Delta T}{2}\right)\right]\right\},
$$

where $\sigma$ represents the material strength, $\sigma_{0}$ is the strength at room temperature, $\sigma_{r}$ is the residual strength, $T$ represents the temperature, $T_{g}$ is the glass transition temperature, and $\Delta T$ is the temperature variation of the glass transition region of the polymer matrix.

The semiempirical model described in Equation (11) is close to a hyperbolic tangent function. As shown in Figure 8, the hyperbolic function has two asymptotes, connected by a linear transition zone. The region of the transition zone is determined by the glass transition temperature of the resin matrix and the strength change of the composite material. The environmental temperature and humidity determine the effect on the glass transition temperature.

For a unidirectional FRP composite, although its strength is mainly governed by the reinforced fibers, the modulus of the matrix and the adhesion between fibers and matrix also have significant effects on the strength. When the ambient temperature $T<T_{g}$, the storage modulus of the resin matrix and the fiber/matrix adhesion are maintained in a stable state, and the mechanical properties of the composite material are correspondingly constant. When $T_{g}<T<T_{\text {efg }}$, the softened matrix causes the decreases in adhesion, which indicates the occurrence of the strength degradation of the composite materials. When $T>T_{\text {efg }}$, the significant decrease of storage modulus and strength of the matrix results in the loss of the ability of the matrix to transfer stress between fibers. At this time, the strength degradation of the composites is basically completed and reaches a new relatively stable state, in which the strength properties are mainly controlled by the fibers.

Attukur Nandagopal et al. [33] improved Cao's model to predict the strength degradation of CFRP in hydrothermal environments. Two- and three-parameter Weibull distributions were used to establish the statistical distribution of the dry and hydrothermal aged material strength data, 


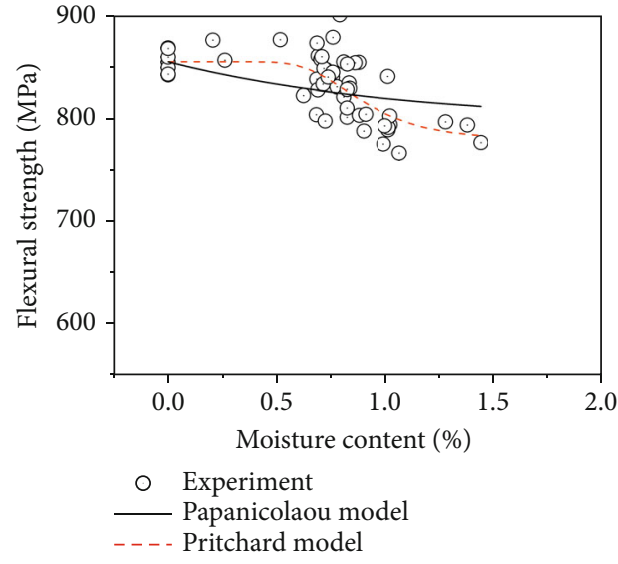

(a)

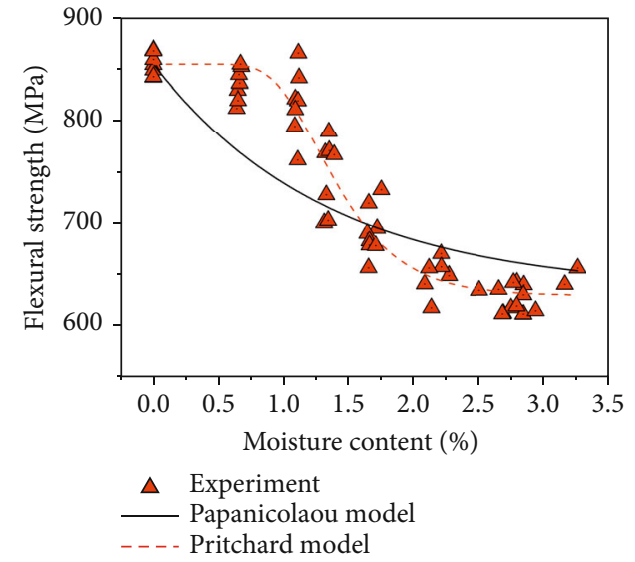

(b)

Figure 7: Experimental data fitted to moisture content: (a) hydrothermal aging and (b) acid aging.

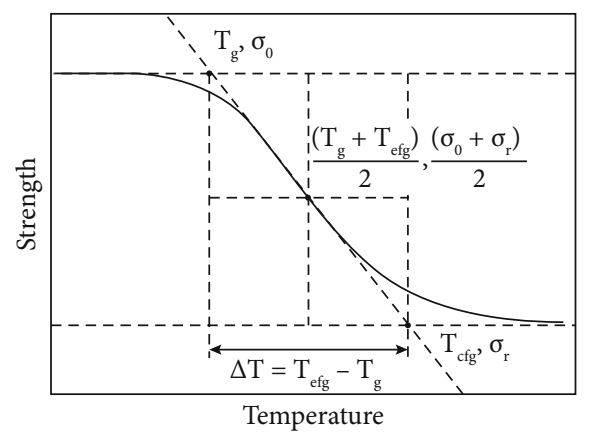

FIGURE 8: Hyperbolic tangent functions describing the strength degradation due to ambient temperature.

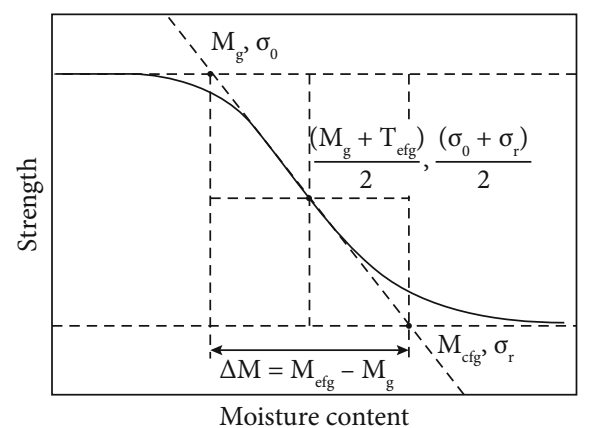

FIGURE 9: Hyperbolic tangent functions describing the strength degradation due to moisture content.

respectively. A shift of the aged strength variation graph due to the temperature variation was found, which indicated the similar aging mechanism of the temperature and moisture content. According to Rajaram's assumption, the curve shown in Figure 9 was transformed as shown in Figure 9.

From the data shown in Figure 7, the characteristic of the hyperbolic tangent function is quite obvious, therefore, Cao's model is transferred into

$$
\begin{aligned}
\sigma= & \frac{\sigma_{0}+\sigma_{r}}{2}+\frac{\sigma_{0}-\sigma_{r}}{2} \tan h \\
& \cdot\left\{\frac{-1}{\left(M_{e f g}-M_{g}\right) / 2}\left[M-\left(M_{g}+\frac{M_{e f g}-M_{g}}{2}\right)\right]\right\},
\end{aligned}
$$

where $M_{g}$ is the critical moisture content at the beginning of the strength degradation stage and $M_{e f g}$ is the critical moisture content at the end of the strength degradation stage.

In this research, the coordinates of the intersection points $\left(M_{g}, \sigma_{0} ; M_{e f g}, \sigma_{r}\right)$ were approximated by the asymptote and the tangent of the transition area. When the moisture content $M$ approached $M_{g}$, the strength degradation of the composite material gradually occurred. In the period of the strength degradation, the strength decreased linearly with the increase of moisture content until the moisture content $M$ approached $M_{e f g}$. Meanwhile, the strength degraded slowly and eventually reached a new stable state. According to the test data, the empirical parameters were preliminarily estimated as follows: $M_{g}=0.85 \%, M_{\text {efg }}=2.1 \%, \sigma_{0}=854$ $\mathrm{MPa}$, and $\sigma_{r}=630 \mathrm{MPa}$. The parameters of hydrothermal aging test were as follows: $M_{g}=0.7 \%, M_{e f g}=1.0 \%, \sigma_{0}=$ $854 \mathrm{MPa}$, and $\sigma_{r}=780 \mathrm{MPa}$. The estimated parameters were used as input variables of Equation (12) for data fitting. By reaching the critical moisture content $M_{e f g}$, the flexural strength under the two aging conditions degraded by $8.77 \%$ and $26.43 \%$, respectively. As shown in Figure 10 and Table 2, both the current model and the Pritchard model have achieved good fitting results. The advantage of the current model is that the main parameters $\sigma_{0}$ and $\sigma_{r}$ are easily obtained from bending tests; furthermore, $M_{g}$ and $M_{\text {efg }}$ are conveniently estimated from the distribution of strength with moisture content.

4.4. Flexural Failure Modes. Microstructure images of flexural failure shown in Figure 11 reveal the damage regions of the dry specimen and acid-aged specimens under three- 


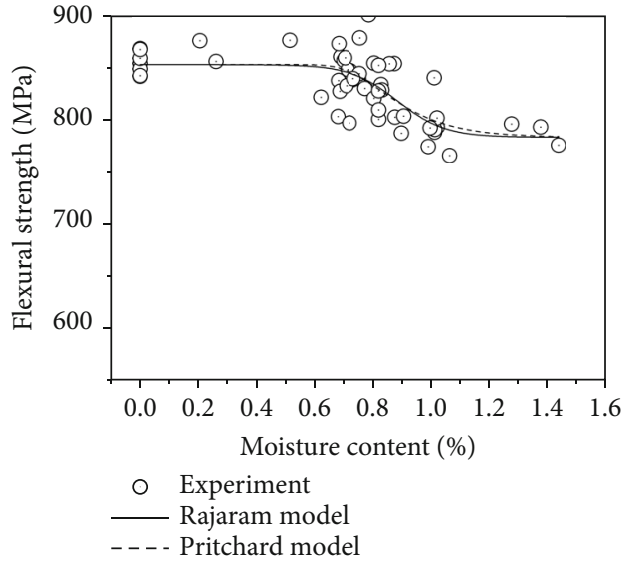

(a)

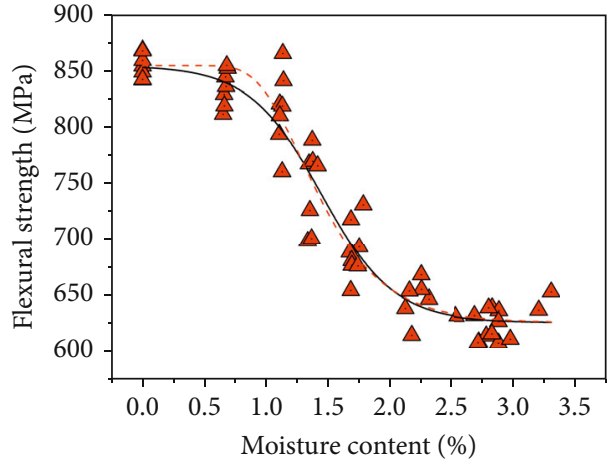

$\Delta$ Experiments

- Rajaram model - . - . Pritchard model

(b)

Figure 10: Experimental data fitted to empirical models: (a) hydrothermal aging and (b) acid aging.

TABLE 2: Empirical parameters of empirical models through nonlinear regression analysis.

\begin{tabular}{|c|c|c|c|c|c|}
\hline \multirow{2}{*}{ Properties } & \multicolumn{5}{|c|}{ Rajaram model } \\
\hline & $\sigma_{0}(\mathrm{MPa})$ & $\sigma_{r}(\mathrm{MPa})$ & $M_{g}(\%)$ & $M_{e f g}(\%)$ & Adj. $R$-square \\
\hline Hydrothermal aging & 853.44 & 784.00 & 0.72 & 1.04 & 0.504 \\
\hline \multirow[t]{3}{*}{ Acid aging } & 855.04 & 628.49 & 0.84 & 1.98 & 0.931 \\
\hline & \multicolumn{5}{|c|}{ Pritchard model } \\
\hline & $\mathrm{a}$ & $\mathrm{b}$ & c & $\mathrm{d}$ & Adj. $R$-square \\
\hline Hydrothermal aging & 69.44 & 502.94 & 7.47 & 783.99 & 0.506 \\
\hline Acid aging & 225.26 & 36.94 & 2.85 & 629.72 & 0.929 \\
\hline
\end{tabular}

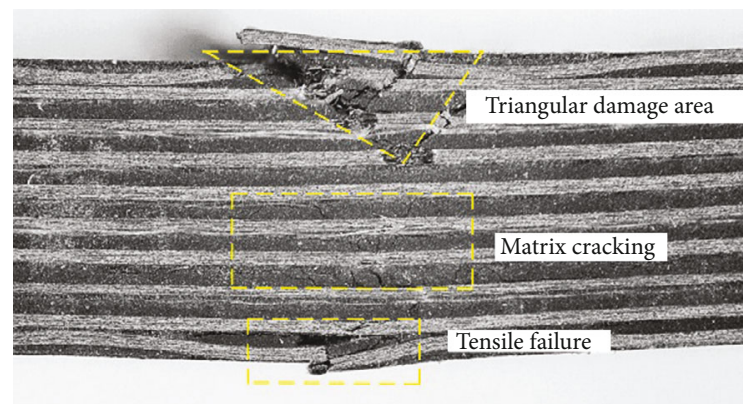

(a)

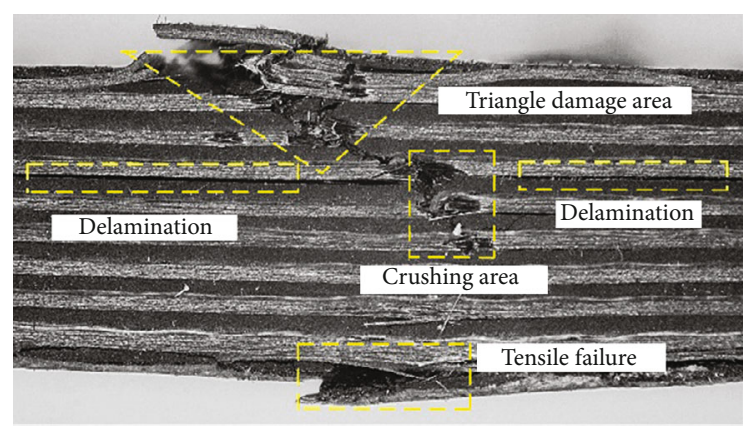

(c)

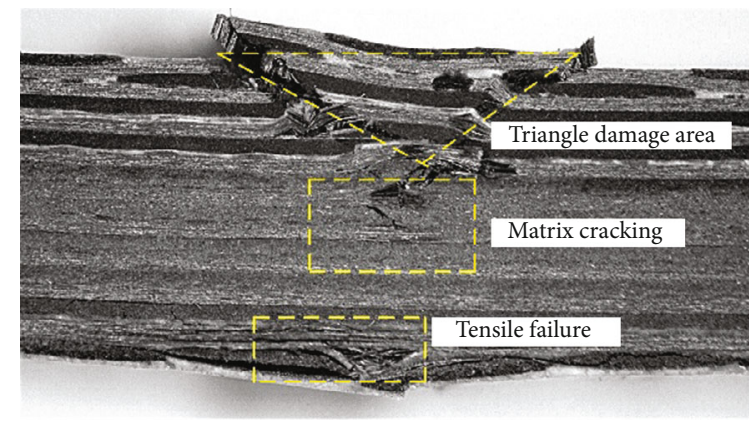

(b)

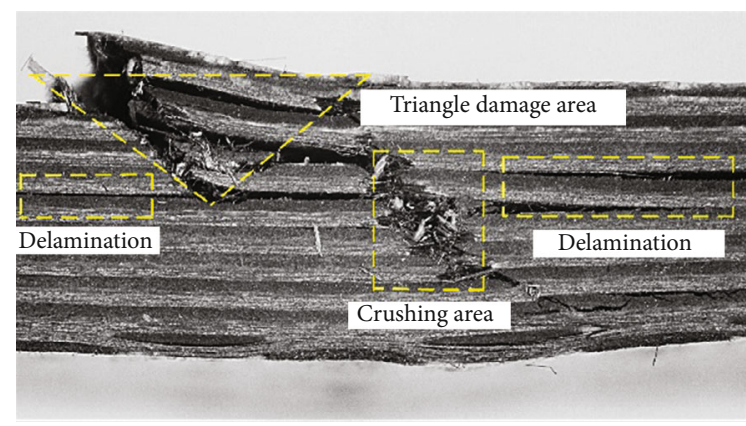

(d)

FIGURE 11: Flexural failure modes of dry specimen and acid aged specimens: (a) dry specimen, (b) 20-day aged specimen, (c) 60-day aged specimen, and (d) 120-day aged specimen. 


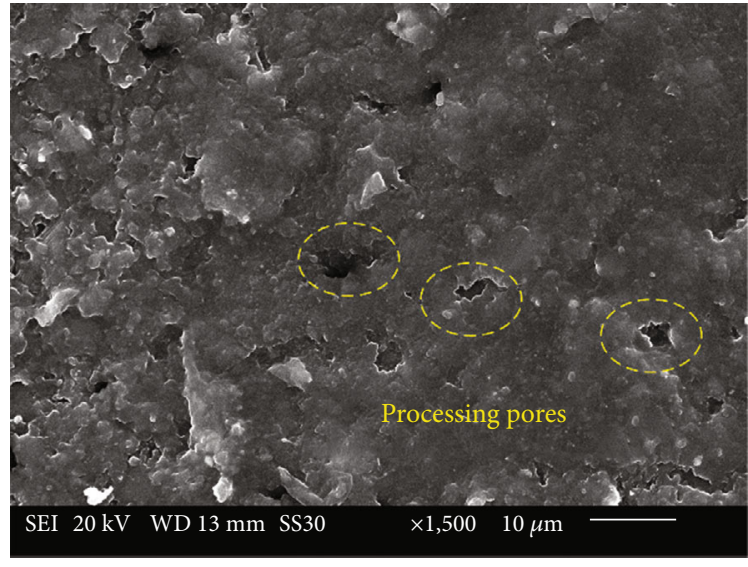

(a)

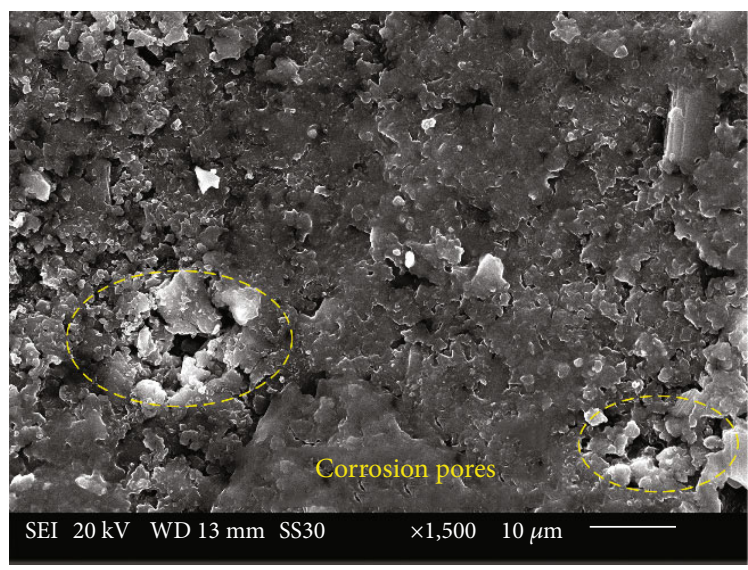

(c)

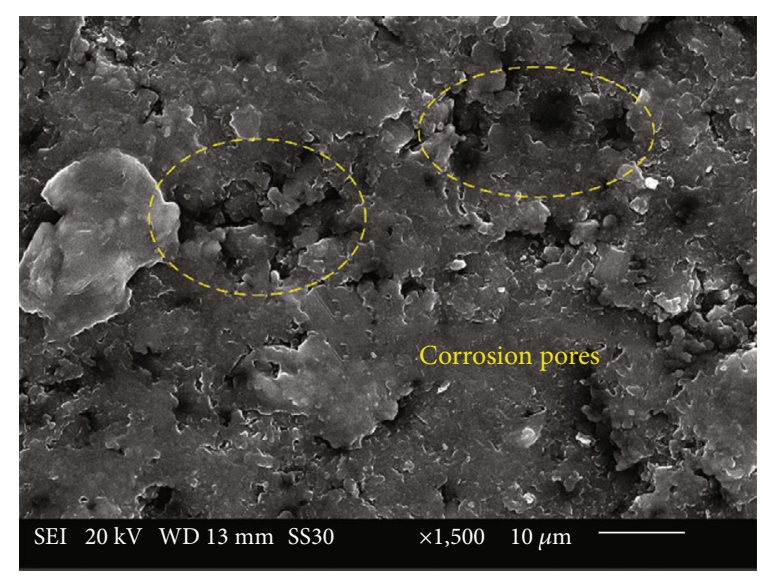

(b)

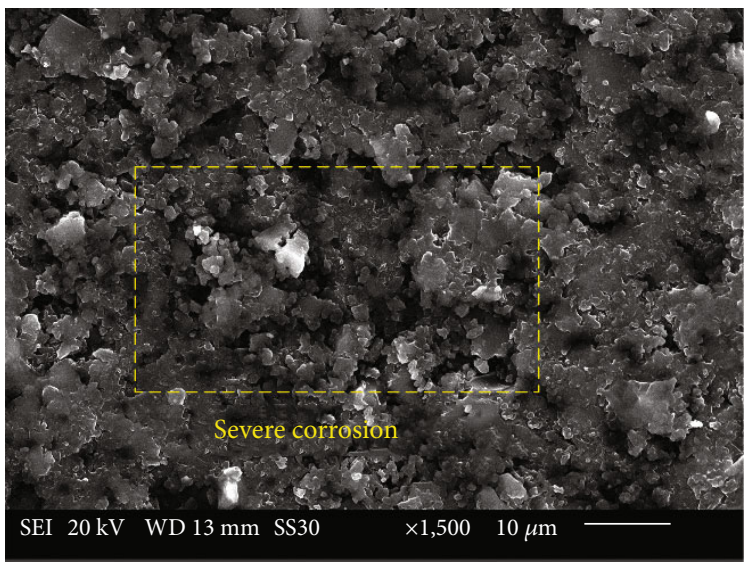

(d)

FIGURE 12: SEM photographs of surface area: (a) dry specimen, (b) 20-day aged specimen, (c) 60-day aged specimen, and (d) 120-day aged specimen.

point bending load. The failure modes due to bending load can be summarized as follows: (1) triangular area formed by fiber buckling and resin matrix crushing near the top side due to compressive stress, (2) tensile failure at the bottom side, (3) in-plane and out-of-plane matrix cracking, and (4) delamination. With the progress of the aging test, the area of the triangular damage area caused by the compressive stress near the top side has grown larger. The fiber buckling and the matrix crushing caused by compressive stress produced a crack crossing several plies, and the crack continued to propagate along thickness direction. As the increasing of the moisture content, delamination completely propagates that results in the fracture of the specimen. In 120-day aged specimen, the compressive delamination leads to the further damage of the triangular damage area. The difference of failure modes between aged and unaged specimens indicates the degradation of interface between fibers and matrix, which results in the matrix gradually which loses the ability to transfer stress between reinforced fibers.

4.5. SEM Observations. The SEM photographs of the acid aged specimens at the surface area and delamination area are shown in Figures 12 and 13. As shown in Figure 12(a), despite the existence of small pores generated during the curing process, the surface of the dry specimen is relatively smooth. From the information contained in Figures 12(b)12(d), it is obvious that due to the corrosion of acidic substances, the resin surface becomes rough, and the corrosion extends along the pores to the inside of the specimen. The larger pores caused by corrosion are the main reason for the higher moisture content of the acid aging specimens than the hydrothermal aging specimens.

Figure 13 shows the microscopic morphology of the dry specimen and aged specimen in delamination failure area. Under dry conditions, the carbon fiber has been well covered by the matrix; the failure mainly occurs in the resin matrix. The bulk of resin attached to the fiber indicates that the interface between the fiber and the matrix is well bonded. After 20 days of aging test, although the micromorphology of the damaged area has slightly changed, the fiber and the resin matrix still maintain a good bonding strength. After 60 days of immersion, the composite material has undergone significant changes. Pores and microcracks caused by acidic medium corrosion frequently appear in the area of the resin matrix; meanwhile, the material strength has degraded seriously. After 60 days of immersion, the composite material has undergone significant changes. Porosity and microcracks caused by acidic medium corrosion frequently 


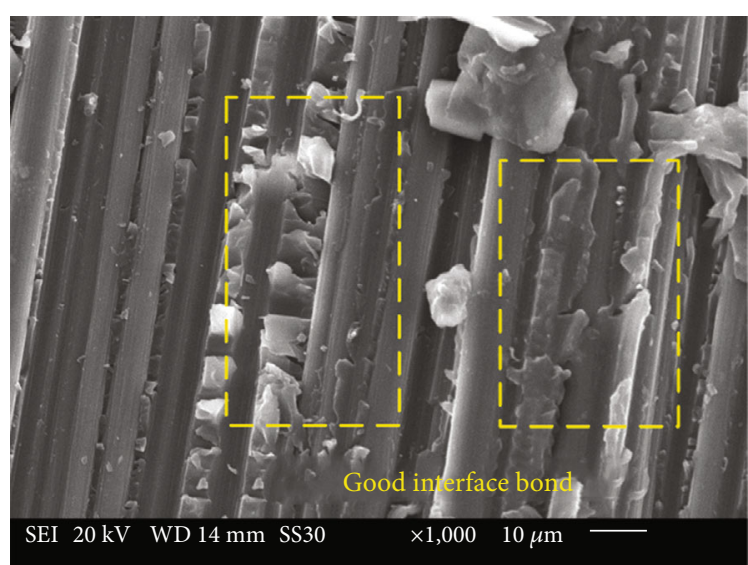

(a)

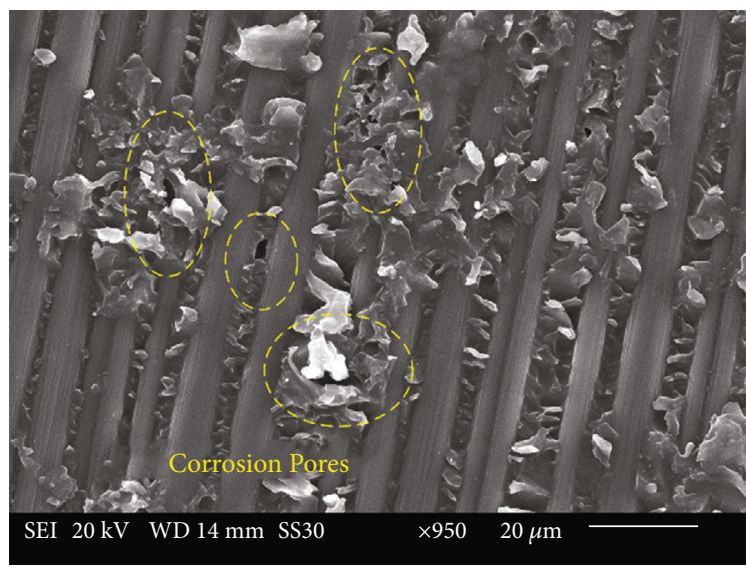

(c)

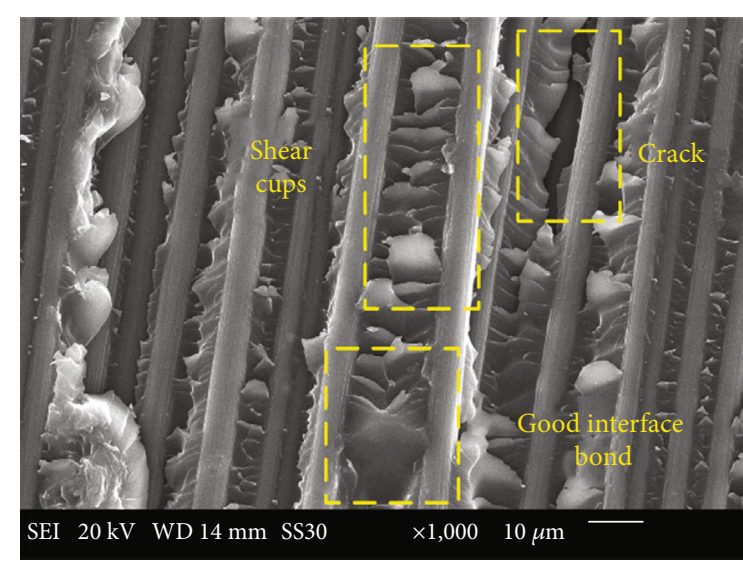

(b)

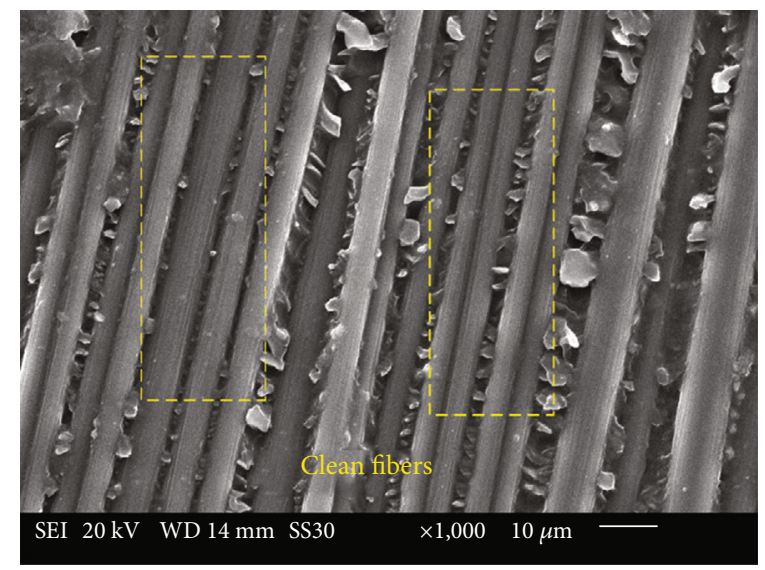

(d)

FIGURE 13: SEM photographs of delamination area: (a) dry specimen, (b) 20-day aged specimen, (c) 60-day aged specimen, and (d) 120-day aged specimen.

appear in the resin matrix area, and the degree of contact between the fiber and matrix is significantly reduced, and the material strength at this time is seriously degraded. When the aging test is over, the increase of bound water molecules will have a destructive effect on the resin matrix and the fiber/resin interface, severely destroying the microstructure of the composite material. The bending strength at this time has reached a new equilibrium state.

\section{Conclusions}

In this paper, the CFRP composite material is immersed in $60^{\circ} \mathrm{C}$ deionized water and $\mathrm{pH}=2.0$ acid solution to simulate the mechanical performance degradation of solar UAV structural materials under the influence of acid rain environment.

Under hydrothermal conditions, the moisture absorption content of the composite material reached a saturated state of $1.07 \%$, and the average flexural strength decreased from $854 \mathrm{MPa}$ with a decrease of $8.77 \%$. In the acid aging test, the moisture absorption content did not reach the saturation state. The maximum moisture absorption rate obtained at the end of the test was $2.88 \%$, and the average bending strength dropped with a decrease of $26.43 \%$.
The empirical models controlled by aging time and moisture absorption were used to describe the flexural strength degradation behaviour of CFRP composites under two aging conditions. Among them, Pritchard's model and Rajaram's model fit the experimental data best.

The SEM observation of the specimen at surface and the delamination damage area showed that although the moisture absorption increased rapidly in the early stage of the aging test, the microstructure of the composite material did not change significantly. When the critical water content is reached, the resin matrix undergoes irreversible chemical changes, and the strength of the interface between the fiber and matrix is severely reduced, which leads to the degradation of the bending strength of the composite material.

The research results provide theoretical and data support for the application of CFRP composites in solar UAVs and play an important role in the subsequent UAV structure design and research.

\section{Data Availability}

The experimental data used to support the findings of this study are available from the corresponding author upon request. 


\section{Conflicts of Interest}

The authors declare that they have no conflicts of interest.

\section{Acknowledgments}

This research was supported by the Key $\mathrm{R} \& \mathrm{D}$ Projects in Shaanxi Province (S2021-YF-YBGY-1244).

\section{References}

[1] C. Soutis, "Introduction: engineering requirements for aerospace composite materials," Polymer Composites in the Aerospace Industry, vol. 1, pp. 1-18, 2015.

[2] J. M. Lee, B. J. Min, J. H. Park, D. H. Kim, B. M. Kim, and D. C. Ko, "Design of lightweight CFRP automotive part as an alternative for steel part by thickness and lay-up optimization," Materials, vol. 12, no. 14, p. 2309, 2019.

[3] A. Zhou, R. Qin, C. L. Chow, and D. Lau, "Structural performance of FRP confined seawater concrete columns under chloride environment," Composite Structures, vol. 216, pp. 12-19, 2019.

[4] L. Mishnaevsky, K. Branner, H. N. Petersen, J. Beauson, M. McGugan, and B. Sørensen, "Materials for wind turbine blades: an overview," Materials, vol. 10, no. 11, p. 1285, 2017.

[5] P. Alam, C. Robert, and C. M. Ó Brádaigh, “Tidal turbine blade composites - a review on the effects of hygrothermal aging on the properties of CFRP," Composites Part B: Engineering, vol. 149, pp. 248-259, 2018.

[6] E. Cestino, "Design of solar high altitude long endurance aircraft for multi payload \& operations," Aerospace Science and Technology, vol. 10, no. 6, pp. 541-550, 2006.

[7] B. Dao, J. Hodgkin, J. Krstina, J. Mardel, and W. Tian, “Accelerated aging versus realistic aging in aerospace composite materials. I. The chemistry of thermal aging in a lowtemperature-cure epoxy composite," Journal of Applied Polymer Science, vol. 102, no. 5, pp. 4291-4303, 2006.

[8] V. Bellenger, J. Decelle, and N. Huet, "Ageing of a carbon epoxy composite for aeronautic applications," Composites Part B: Engineering, vol. 36, no. 3, pp. 189-194, 2005.

[9] F. Almudaihesh, K. Holford, R. Pullin, and M. Eaton, “The influence of water absorption on unidirectional and 2D woven CFRP composites and their mechanical performance," Composites Part B: Engineering, vol. 182, p. 107626, 2020.

[10] X. Cheng, Q. Zhang, J. Zhang, X. Guo, and Z. Niu, "Parameters prediction of cohesive zone model for simulating composite/adhesive delamination in hygrothermal environments," Composites Part B: Engineering, vol. 166, pp. 710-721, 2019.

[11] A. Garg and H. D. Chalak, "A review on analysis of laminated composite and sandwich structures under hygrothermal conditions," Thin-Walled Structures, vol. 142, pp. 205-226, 2019.

[12] P. Feng, J. Wang, Y. Wang, D. Loughery, and D. Niu, "Effects of corrosive environments on properties of pultruded GFRP plates," Composites Part B: Engineering, vol. 67, pp. 427-433, 2014.

[13] M. H. Banna, J. Shirokoff, and J. Molgaard, "Effects of two aqueous acidic solutions on polyester and bisphenol A epoxy vinyl ester resins," Materials Science and Engineering: A, vol. 528, no. 4-5, pp. 2137-2142, 2011.

[14] N. Mortas, O. Er, P. N. B. Reis, and J. A. M. Ferreira, "Effect of corrosive solutions on composites laminates subjected to low velocity impact loading," Composite Structures, vol. 108, pp. 205-211, 2014.

[15] A. M. Amaro, P. N. B. Reis, M. A. Neto, and C. Louro, "Effects of alkaline and acid solutions on glass/epoxy composites," Polymer Degradation and Stability, vol. 98, no. 4, pp. 853862, 2013.

[16] M. Kanerva, J. Jokinen, E. Sarlin et al., "Lower stiffness of GFRP after sulfuric acid-solution aging is due to degradation of fibre-matrix interfaces?,” Composite Structures, vol. 212, pp. 524-534, 2019.

[17] R. Kattaguri, A. O. Fulmali, R. K. Prusty, and B. C. Ray, "Effects of acid, alkaline, and seawater aging on the mechanical and thermomechanical properties of glass fiber/epoxy composites filled with carbon nanofibers," Journal of Applied Polymer Science, vol. 137, no. 10, p. 48434, 2019.

[18] K. K. Phani and N. R. Bose, "Hydrothermal ageing of CSMlaminate during water immersion-an acousto-ultrasonic study," Journal of Materials Science, vol. 21, no. 10, pp. 3633-3637, 1986.

[19] L. Gautier, B. Mortaigne, and V. Bellenger, "Interface damage study of hydrothermally aged glass-fibre-reinforced polyester composites," Composites Science and Technology, vol. 59, no. 16, pp. 2329-2337, 1999.

[20] P. Sun, Y. Zhao, Y. Luo, and L. Sun, "Effect of temperature and cyclic hygrothermal aging on the interlaminar shear strength of carbon fiber/bismaleimide (BMI) composite," Materials \& Design, vol. 32, no. 8-9, pp. 4341-4347, 2011.

[21] F. Guo, P. Huang, Y. Q. Li, N. Hu, and S. Y. Fu, "Multiscale modeling of mechanical behaviors of carbon fiber reinforced epoxy composites subjected to hygrothermal aging," Composite Structures, vol. 256, p. 113098, 2021.

[22] J. D. Tanks, S. R. Sharp, and D. K. Harris, "Kinetics of in-plane shear degradation in carbon/epoxy rods from exposure to alkaline and saline environments," Composites Part B: Engineering, vol. 110, pp. 204-212, 2017.

[23] M. G. Phillips, "Prediction of long-term stress-rupture life for glass fibre-reinforced polyester composites in air and in aqueous environments," Composites, vol. 14, no. 3, pp. 270-275, 1983.

[24] G. Pritchard and S. D. Speake, "The use of water absorption kinetic data to predict laminate property changes," Composites, vol. 18, no. 3, pp. 227-232, 1987.

[25] G. C. Papanicolaou, T. V. Kosmidou, A. S. Vatalis, and C. G. Delides, "Water absorption mechanism and some anomalous effects on the mechanical and viscoelastic behavior of an epoxy system," Journal of Applied Polymer Science, vol. 99, no. 4, pp. 1328-1339, 2006.

[26] A. G. Gibson, Y. . S. Wu, J. T. Evans, and A. P. Mouritz, "Laminate theory analysis of composites under load in fire," Journal of Composite Materials, vol. 40, no. 7, pp. 639-658, 2005.

[27] Shenghu Cao, Xin Wang, and Zhishen Wu, "Evaluation and prediction of temperature-dependent tensile strength of unidirectional carbon fiber-reinforced polymer composites," Journal of Reinforced Plastics and Composites, vol. 30, no. 9, pp. 799-807, 2011.

[28] I. B. C. M. Rocha, S. Raijmaekers, R. P. L. Nijssen, F. P. van der Meer, and L. J. Sluys, "Hygrothermal ageing behaviour of a glass/epoxy composite used in wind turbine blades," Composite Structures, vol. 174, pp. 110-122, 2017.

[29] P. Davies and M. Arhant, "Fatigue behaviour of acrylic matrix composites: influence of seawater," Applied Composite Materials, vol. 26, no. 2, pp. 507-518, 2019. 
[30] ASTM D7264/D7264M-15, Standard Test Method for Flexural Properties of Polymer Matrix Composite Materials, ASTM, West Conshohocken, PA, USA, 2015.

[31] ASTM D5229/D5229M-14, Standard Test Method for Moisture Absorption Properties and Equilibrium Conditioning of Polymer Matrix Composite Materials, ASTM, West Conshohocken, PA, USA, 2014.

[32] A. Zafar, F. Bertocco, J. Schjødt-Thomsen, and J. C. Rauhe, "Investigation of the long term effects of moisture on carbon fibre and epoxy matrix composites," Composites Science and Technology, vol. 72, no. 6, pp. 656-666, 2012.

[33] R. Attukur Nandagopal, C. Gin Boay, and S. Narasimalu, "An empirical model to predict the strength degradation of the hygrothermal aged CFRP material," Composite Structures, vol. 236, p. 111876, 2020. 